\title{
Pneumatosis cystoides intestinalis secondary to increased intraluminal air pressure of previous colonoscopies
}

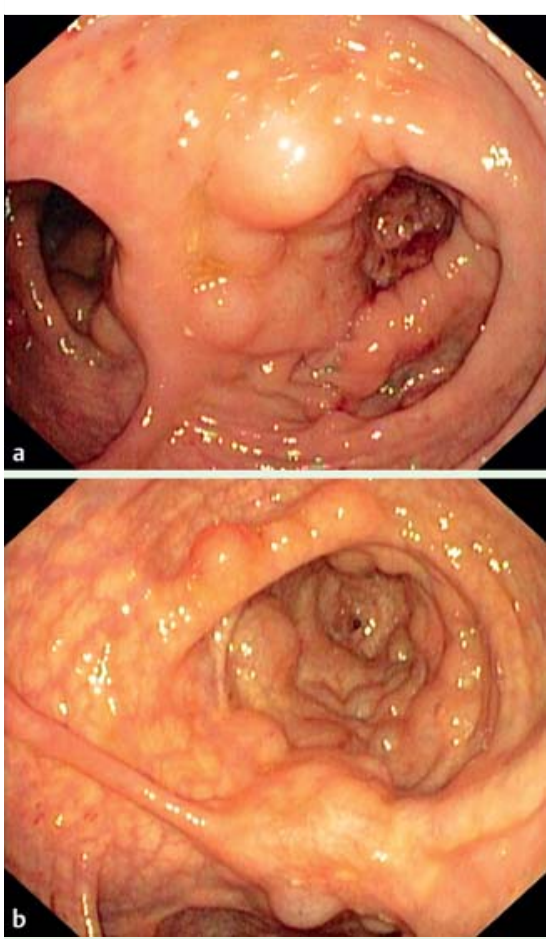

Fig. 1 Pneumatosis cystoides intestinalis. a, b Multiple sessile, ball-shaped subepithelial nodules are seen at the colonic anastomosis.

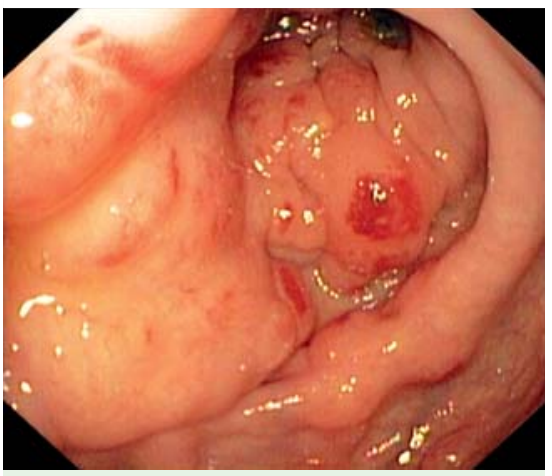

Fig. 2 Some of the nodules are covered with a reddish mucosa.

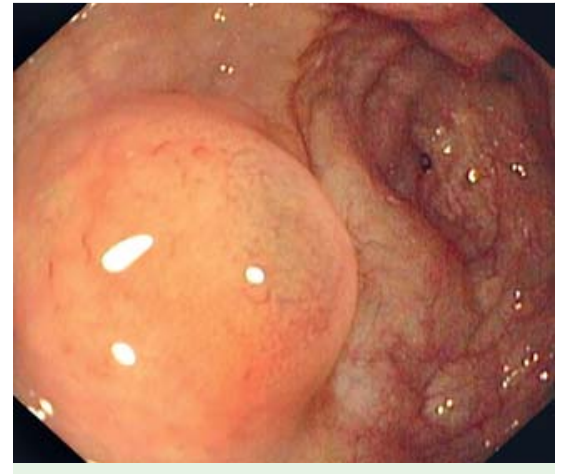

Fig. 3 The mucosa overlying most of the nodules is normal.

A 67-year-old man was referred for surveillance colonoscopy because of his past medical history of a segmental colonic resection in 2010 for colorectal adenocarcinoma. He underwent colonoscopy in 2011 and again in 2013, with endoscopic polypectomy carried out during both procedures. He was asymptomatic. In 2014, multiple sessile, ball-shaped subepithelial nodules were identified at the colonic anastomosis, suggestive of pneumatosis cystoides intestinalis ( Fig. 1). Some of the nodules were covered with a reddish mucosa ( Fig. 2), but the mucosa overlying most of the nodules was normal ( Fig.3). Biopsies were done to confirm the nature of the cystic lesions ( $\bullet$ Fig.4), and an injection needle was used to puncture the cyst and determine the nature of the target, with the release of "air" and cyst collapse ( Video 1). Mucosal histology confirmed the diagnosis ( $\bullet$ Fig. 5 ).

Pneumatosis cystoides intestinalis is a rare clinical entity characterized by gaseous cystic collections in the wall of the gastrointestinal tract [1]. The cysts contain nitrogen, hydrogen, and carbon dioxide. The clinical manifestations are nonspecific, with various presenting symp-

\section{Video 1}

An injection needle is used to puncture the cyst and determine the nature of the target, with the release of "air" and cyst collapse.

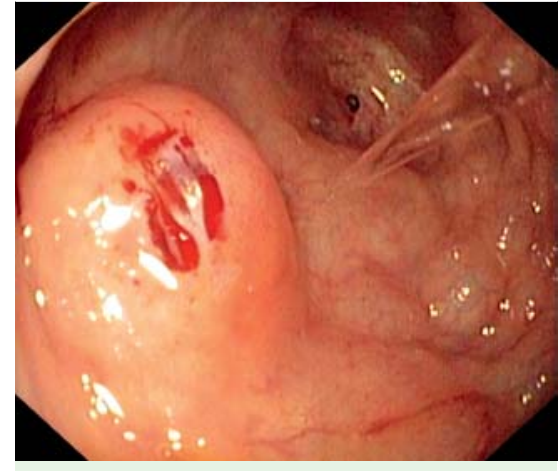

Fig. 4 Biopsies of the submucosal lesions were performed, revealing the air cysts underneath the mucosa.

toms. Several theories for the etiology of pneumatosis cystoides intestinalis have been proposed; however, we believe that the mechanical hypothesis may have been the most likely one in our patient. As a result of increased intraluminal air pressure during previous colonoscopies, air may push through tears in the mucosa and become entrapped within the bowel wall [2]. Visualization of the gas-filled cysts on colonoscopy may confirm the diagnosis. Biopsy specimens of the submucosal lesions can be taken to reveal the air cysts underneath the mucosa. These may deflate if punctured, with complete resolution of the cystic cavities [3]. The importance of an endoscopic diagnosis lies in distinguishing the lesions from colonic polyps, given that the risk for perforation is increased if polypectomy has been done. The disease may be managed conservatively because some lesions disappear spontaneously.

\section{Endoscopy_UCTN_Code_CCL_1AD_2AJ}

\section{Competing interests: None}

\section{Eduardo Rodrigues-Pinto", Rosa Ramalho ${ }^{1}$, Helena Baldaia², Guilherme Macedo ${ }^{1}$}

${ }^{1}$ Gastroenterology Department, Centro Hospitalar São João, Porto, Portugal

2 Pathology Department, Centro Hospitalar São João, Porto, Portugal 


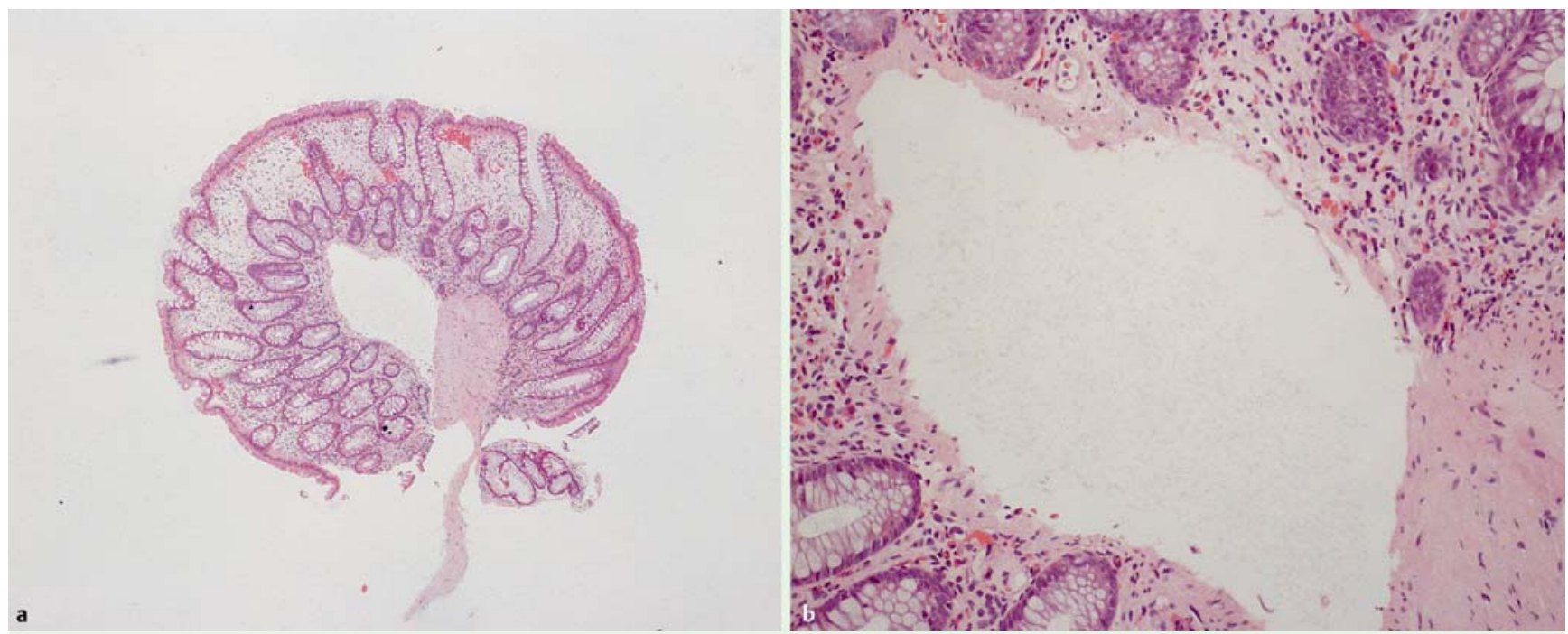

Fig. 5 Colonic histology: traces of a cystic lesion under the colonic muscularis mucosae with no lining, consistent with the clinical suspicion of pneumatosis cystoides intestinalis. a Hematoxylin and eosin (H\&E), original magnification $\times 40$; b original magnification $\times 200$.

\section{References}

1 Wu $L L$, Yang YS, Dou $Y$ et al. A systematic analysis of pneumatosis cystoids intestinalis. World J Gastroenterol 2013; 19: $4973-$ 4978

2 Waring JP, Manne RK, Wadas DD et al. Mucosal pseudolipomatosis: an air pressurerelated colonoscopy complication. Gastrointest Endosc 1989; 35: 93-94

3 Rodrigues-Pinto E, Pereira P, Macedo G. Primary pneumatosis cystoides intestinalis (with video). Gastrointest Endosc 2014; 79: $1008-1009$
Bibliography

DOI http://dx.doi.org/

10.1055/s-0034-1377985

Endoscopy 2014; 46: E572-E573

(c) Georg Thieme Verlag KG

Stuttgart - New York

ISSN 0013-726X

\section{Corresponding author}

Eduardo Rodrigues-Pinto, MD

Gastroenterology Department

Centro Hospitalar São João

Alameda Professor Hernâni Monteiro

4200-319 Porto

Portugal

Fax: +351-22-551-3601

edu.gil.pinto@gmail.com 